\title{
yve $B$, encoding endolevanase LevB, is part of the sacB-yveB-yveA levansucrase tricistronic operon in Bacillus subtilis
}

\author{
Yannick Pereira, Marie-Françoise Petit-Glatron and Régis Chambert
}

Author for correspondence: Régis Chambert. Tel: +33 144274719. Fax: +33144275994.

e-mail: chambert@ccr.jussieu.fr

Institut Jacques Monod, Laboratoire Génétique et Membranes, CNRS Universités Paris 6 et Paris 7, Tour 43, 2 place Jussieu, 75251 Paris Cedex 05, France

\begin{abstract}
Transcription of sacB, yveB and yveA, three clustered genes on the Bacillus subtilis chromosome, is simultaneously induced by sucrose. Northern blotting analyses with specific probes showed three distinct mRNAs: a monocistronic $1.7 \mathrm{~kb}$ sacB mRNA, a bicistronic $3.3 \mathrm{~kb}$ sacB-yveB mRNA and a tricistronic $4.9 \mathrm{~kb}$ sacB-yve $B-y v e A$ mRNA. These results indicate that sacB, encoding levansucrase, is the proximal gene of a sucrose-inducible operon that includes the two other genes. The yield of the full-length transcript is lower than that of the bicistronic transcript, whose yield is itself lower than that of the monocistronic transcript. This suggested that the $3^{\prime}$ terminal parts of sacB and $y v e B$ genes worked as internal terminator structures. The protein encoded by yve $B$, which remains anchored to the membrane, displays an endolevanase activity, which, coupled with exolevanase activity of SacB, leads to a complete degradation of levan, a branched fructosyl polymer. It is proposed to rename yveB as levB.
\end{abstract}

Keywords: levanase, levansucrase operon, sucrose metabolism, degU32(Hy) mutant

\section{INTRODUCTION}

Identification of the various genes involved in the metabolism of sucrose by Bacillus subtilis is mainly based on the seminal work of Lepesant et al. (1972). Of the seven loci characterized, the $s a c B$ locus was predicted to include only the gene encoding levansucrase and was not expected to be organized into a transcriptional unit involving the adjacent genes. Moreover, the sequence of a $2 \mathrm{~kb}$ fragment of $B$. subtilis genome containing the structural gene encoding levansucrase (Steinmetz et al., 1985) showed that the coding frame of this protein was followed by a region that included a dyad symmetry 13 nt long, which was thought to be a strong rhoindependent transcription terminator. Such a result supported the hypothesis proposed by Lepesant et al. (1972) that the $s a c B$ locus is monogenic. However, examination of the complete sequenced genome of $B$. subtilis (Kunst et al., 1997) showed that no potential promoter was discernible in the short intergenic region between the stop codon of $s a c B$ and the start codon of the predicted downstream gene $y v e B$. Since $y v e B$ encodes a protein displaying a similarity to levanase (encoded by $s a c($ ), it can be anticipated that the product of $y v e B$ plays a role in the metabolism of sucrose. Furthermore, $y v e A$, the adjacent coding frame of $y v e B$, could be part of the same transcription unit, given its proximity to the stop codon of $y v e B$. The protein coded by $y v e A$ displays all the features of a membrane protein. Therefore, we anticipated that the $s a c B, y v e B$ and $y v e A$ genes constitute an operon. Using Northern blot analysis, we tested the hypothesis that the transcription of the three genes was simultaneously induced by sucrose. The positive result obtained prompted us to characterize the cellular location of the protein YveB and its catalytic specificity.

\section{METHODS}

Bacterial strains and culture. Bacillus subtilis QB112 $[\operatorname{sac} A 321, \operatorname{deg} U 32(\mathrm{Hy})]$ was used in this work (Chambert \& Petit-Glatron, 1984). Aerobic cultures were run in a 1.51 fermenter (Bioflo 3000, New Brunswick Scientific). Cells were grown in minimal medium, supplemented with $1.5 \%$ (w/v) glucose as carbon source at the beginning of growth and with $60 \mathrm{mM}$ sucrose added at an $\mathrm{OD}_{600}$ of 0.2 when necessary. When the bacterial suspension reached an $\mathrm{OD}_{600}$ of 6 , fresh minimal medium containing $1 \%(\mathrm{w} / \mathrm{v})$ glucose was fed at a constant rate equal to that of the cell suspension outflow $\left(660 \mathrm{ml} \mathrm{h}^{-1}\right) . \mathrm{pH}$ and temperature were controlled and maintained at values of $7 \cdot 0$ and $37{ }^{\circ} \mathrm{C}$, respectively. Solubilized $\mathrm{O}_{2}$ was measured with a Clark electrode and $85 \% \quad \mathrm{O}_{2}$ saturation was maintained by bubbling through the culture. The speed of agitation was 800 r.p.m. Under these conditions, 
Table 1. Oligonucleotides used in this study

\begin{tabular}{|c|c|c|}
\hline Oligonucleotide & Sequence $\left(5^{\prime}-3^{\prime}\right)^{*}$ & $\begin{array}{c}\text { Restriction site at } 5^{\prime} \\
\text { end }\end{array}$ \\
\hline yveA1 & GGGATGGGAGCCATCTTTGGATCAGCGTGGCT & \\
\hline yveA2 & GCAAGCCAGCCTAACCCGAGCATGACC & \\
\hline yveB1 & ACACCCGGGCGCCATGCCGTCTCAGAGG & SmaI \\
\hline yveB2 & TCGCCCGGGAGACGAGGCTGTATGTTCCATCC & SmaI \\
\hline yveB3 & GGAGACGTCATATGGAACTATATAAAAGCAGGCAAATGTAACCG & AatII \\
\hline yveB4 & CCGATATCGCCCAATATGTAACAGAGAATACCGC & EcoRV \\
\hline 5S RNA probe & ACTACCATCGGCGCTGAAGA & \\
\hline
\end{tabular}

* Restriction sites are in bold.

the specific growth rate, $\mu$, remained maximum and constant, at $0.69 \mathrm{~h}^{-1}$. Growth yield was approximately $78 \mathrm{~g}$ biomass $(\text { mol glucose })^{-1}$.

Escherichia coli XL-1 Blue strain was grown in TerB rich medium (Sambrook et al., 1989) containing $150 \mu \mathrm{g}$ ampicillin $\mathrm{ml}^{-1}$.

Isolation and purification of total RNA. RNAs were prepared as described previously (Pereira et al., 2001) from bacteria $(5 \mathrm{ml})$ growing exponentially in the presence or absence of sucrose. All traces of genomic DNA were eliminated during an additional step using a high pure RNA isolation kit (Roche).

Northern blotting. Northern blotting experiments were done essentially as described by Pereira et al. (2001). The $s a c B$ probe (859 nt) was obtained by an EcoRI and KpnI digestion of plasmid pLS50 (Steinmetz et al., 1985). The probes yveB and yve $A$ of, respectively, $817 \mathrm{nt}$ and $818 \mathrm{nt}$, were prepared by PCR using the oligonucleotides shown in Table 1 . Comigration with a molecular mass marker mixture (RNA molecular weight markers, Fermentas) made it possible to estimate the length of the transcripts. RNA bands were revealed by Phosphorimaging and quantified with ImageQuant software (Molecular Dynamics).

Construction of a sacR-yveB fusion and expression of YveB in E. coli. The B. subtilis yveB gene corresponds to an ORF encoding a putative protein of 516 amino acids located $73 \mathrm{nt}$ after the C-terminal stop codon of $s a c B$ gene. This gene was amplified by PCR with primers yveB3 and yveB4 including restriction sites AatII and EcoRV, respectively (Table 1), from the chromosomal DNA of strain QB112 isolated as previously described (Leloup et al., 1997). The amplified blunt-ended fragment was inserted into the pCR $(+)$ vector at the Srfl site after appropriate treatment according to the supplier's recommendations (Stratagene). The yveB fragment was isolated after digestion with AatII and EcoRV and ligated into the pCR (+)sacR vector pGMC9 (Leloup et al., 1999a) digested with the same enzymes. The resulting plasmid pGMC13 was used to transform strain E. coli XL-1 Blue. One transformant was selected and the complete sequence of the gene fusion $s a c R-y v e B$ was checked by sequencing the double-stranded recombinant DNA with the appropriate synthetic oligonucleotides. This strain was grown in parallel with the same strain transformed with pCR $(+)$ vector at $37^{\circ} \mathrm{C}$. A sample of the cell suspensions $(6 \mathrm{ml})$ was withdrawn at an $\mathrm{OD}_{600}$ of 2.5 and centrifuged. The cell pellets were resuspended in $1 \mathrm{ml}$ $0 \cdot 1 \mathrm{M}$ sodium phosphate $\mathrm{pH} 6.5$ containing $100 \mu \mathrm{g}$ chloramphenicol $\mathrm{ml}^{-1}$. After a freeze-thaw cycle, the cells were disrupted by sonication and centrifuged. Levanase activity was assayed in the supernatants as described below.

Substrate and levanase assay. Uniformly labelled $\left[{ }^{14} \mathrm{C}\right]$ levan was obtained by the action of immobilized levansucrase on $\left[{ }^{14} \mathrm{C}\right]$ sucrose (Chambert \& Petit-Glatron, 1993). Levanase was assayed as described by Leloup et al. (1999a).

Fractionation of $\boldsymbol{B}$. subtilis cells. The cell suspension $(250 \mathrm{ml})$ was centrifuged at an $\mathrm{OD}_{600}$ of 2.5 and the bacteria were washed with $10 \mathrm{ml}$ cold buffer containing $2 \mathrm{M} \mathrm{KCl}$. After centrifugation, the cell pellet was resuspended in $10 \mathrm{ml} 0 \cdot 1 \mathrm{M}$ sodium phosphate $\mathrm{pH} 7$ and lysed by incubation for $10 \mathrm{~min}$ at room temperature in the presence of a lysozyme/DNase mixture $\left(1 \mathrm{mg}\right.$ lysozyme $\mathrm{ml}^{-1}, 0 \cdot 1 \mathrm{mg}$ DNase $\mathrm{ml}^{-1}, 0.02 \mathrm{mg}$ $\left.\mathrm{MgCl}_{2} \mathrm{ml}^{-1}\right)$. Disruption was completed by sonication.

The membrane fraction was obtained by centrifuging the suspension twice, first at $5000 \mathrm{~g}$ for $10 \mathrm{~min}$ and then, after discarding the cell debris, at $40000 \mathrm{~g}$ for $30 \mathrm{~min}$. The membrane pellet was resuspended in $2 \mathrm{ml} 0 \cdot 1 \mathrm{M}$ sodium phosphate, $\mathrm{pH} 7$.

\section{RESULTS}

Three different transcripts: sac $B$ mRNA, sacB-yve $B$ mRNA and sacB-yveB-yve $A$ mRNA, are present in the degU32(Hy) strain growing in the presence of sucrose

DNA probes specific to $s a c B, y v e B$ and $y v e A$ were used to probe Northern blots performed with total RNAs prepared from $\operatorname{deg} U 32(\mathrm{Hy})$ cells grown in minimal medium supplemented with glucose in the presence or absence of sucrose. Three bands were observed in the lanes hybridized with the $s a c B$ probe (Fig. 1, lanes 2 and 6) corresponding to transcripts of $1.7,3.3$ and $4.9 \mathrm{~kb}$. Two bands were observed in the lane hybridized with the $y v e B$ probe (Fig. 1, lane 4), corresponding to transcripts of 3.3 and $4.9 \mathrm{~kb}$; only one band of $4.9 \mathrm{~kb}$ was observed in the lane hybridized with the yve A probe (Fig. 1, lane 8). No band corresponding to either the $y v e B$ or the $y v e A$ transcript was observed, suggesting that there were no specific promoters of these two genes nor any subsequent processing of a primary tricistronic transcript into three monocistronic units. These results are consistent with a tricistronic organization of $s a c B$, 


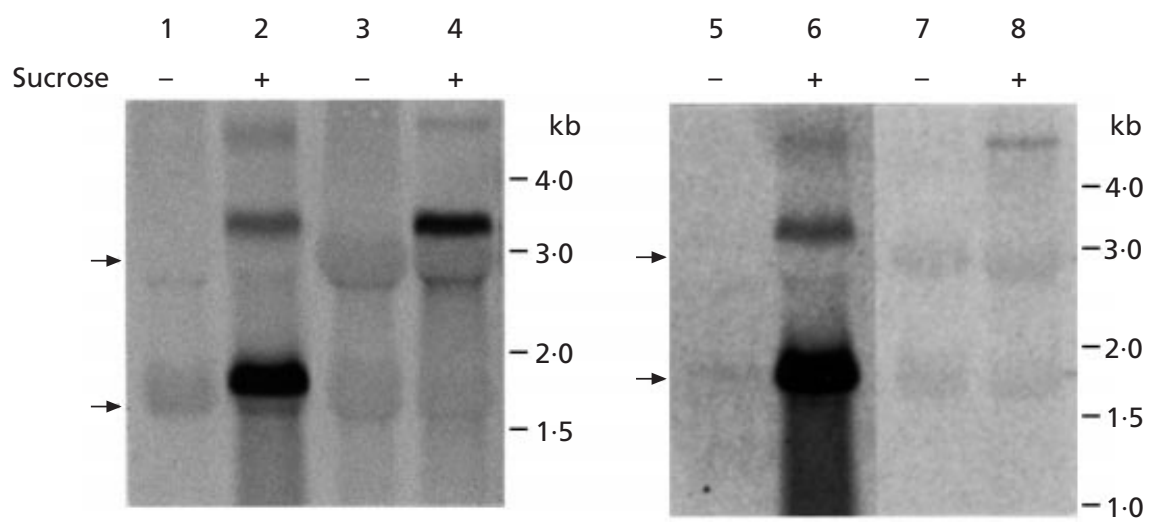

Fig. 1. Northern blotting analysis of $s_{a} B, y v e B$ and $y v e A$ transcripts. Cells of the degU32(Hy) strain were grown in minimal medium in the presence $(+)$ or absence $(-)$ of sucrose. Samples of the culture were withdrawn at $\mathrm{OD}_{600} 1 \cdot 5$, immediately frozen in liquid nitrogen and then treated as described in Methods. Samples (10 $\mu \mathrm{g})$ of each RNA preparation were analysed by Northern blotting. Hybridization was done with the ${ }^{33} \mathrm{P}$-labelled probes described in Methods. Migration of the $23 \mathrm{~S}(2928 \mathrm{nt})$ and $16 \mathrm{~S}(1553 \mathrm{nt})$ rRNAs is indicated by arrowheads on the left. The length of transcripts was estimated by comparing their migration with that of RNA markers (indicated on the right). RNAs prepared from non-induced or induced cells were hybridized with the sacB probe (lanes 1 and 5 or 2 and 6), the $y v e B$ probe (lanes 3 or 4 ) and the yveA probe (lanes 7 or 8 ). (No bands were observed in lanes containing RNAs prepared from non-induced cells: lanes 1, 3, 5 and 7.)

(a)

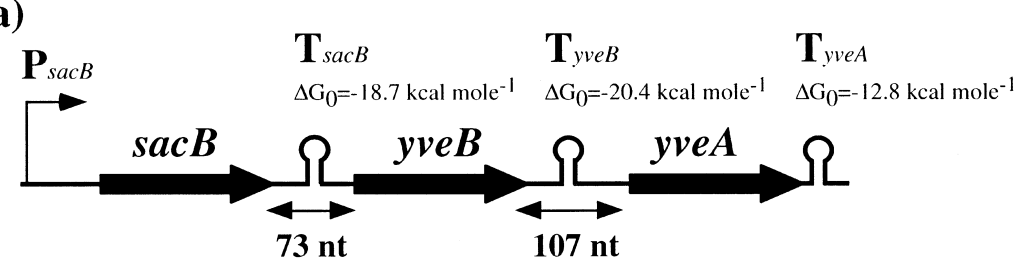

(b)

sacB-yveB intergenic region
TAAaaacgcaaaagaaaatgccgatatcctattggcatttettt tatttcttatc

aacataaaggtgaatcccatATG

yveB-yveA intergenic region

TAAaaacaggggcggcgcaggctgccectgttttttattaggagcggtattctct

gttacatattgggcattgtaaggaatataaggctggtttcaaaggaggaagcgaATG
Fig. 2. Schematic representation of the levansucrase operon. (a) The $\operatorname{sac} B, y v e B$ and yve $A$ genes are represented with their termination loops. The value of their free energies was estimated from the MFOLD program (Zuker et al., 1999). (b) Intergenic regions of $s a c B-y v e B$ and $y v e B-y v e A$. The terminators are underlined and the ShineDalgarno sequence indicated in bold. $y v e B$ and $y v e A$, transcribed exclusively from a common promoter upstream of $s a c B$. In the frame of such a hypothesis, the lower intensity of the bands corresponding to $s a c B-y v e B$ and $s a c B-y v e B-y v e A$ would be the result of partial arrests of the RNA polymerase at the transcription termination loops after $s a c B$ and $y v e B$. Using the MFOLD program (Zuker et al., 1999) we evaluated the free energies of these terminators to be -18.7 and $-20.4 \mathrm{kcal} \mathrm{mol}^{-1}(-78.2$ and $-85.4 \mathrm{~kJ}$ $\mathrm{mol}^{-1}$ ), respectively.

\section{Organization of the levansucrase operon}

The region upstream of $s a c B$ has been shown to include a sigma vegetative promoter (Steinmetz et al., 1985), a short region of dyad symmetry (RAT) (Aymerich \&
Steinmetz, 1992; Tortosa \& Le Coq, 1995), a target of the antiterminator SacY (Crutz et al., 1990), whose active dephosphorylated form is induced in the presence of sucrose, and a structure similar to a transcription terminator (Shimotsu \& Henner, 1986; Steinmetz \& Aymerich, 1986). The structural gene $s a c B$, encoding a precursor of 473 amino acid residues which includes a signal sequence of 29 residues, is immediately followed by a stretch of $73 \mathrm{nt}$ (Fig. 2). This DNA fragment includes a terminator structure and a Shine-Dalgarno consensus sequence (AAAGGTG) 8 nt distant from the ATG start codon of $y v e B$. The structural gene of $y v e B$, encoding a protein of 516 amino acid residues, revealed a putative signal sequence according to SignalP, as reported by Tjalsma et al. (2000). The following open reading frame of 520 amino acid residues encoded by 
(a)

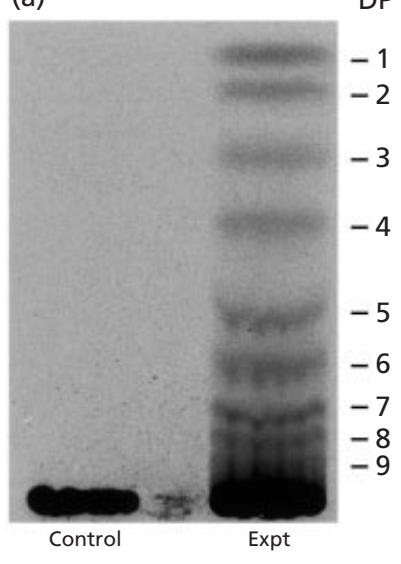

(b)

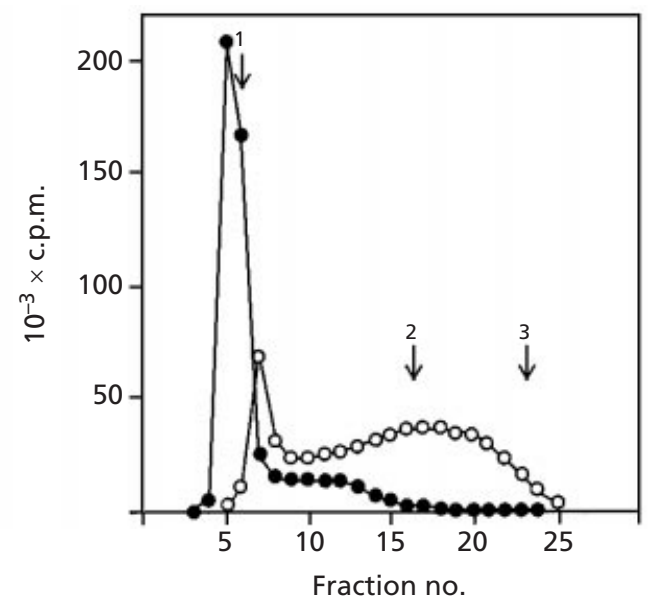

Fig. 3. Levanase activity of $Y v e B$ cloned in E. coli. The reaction mixture $(40 \mu \mathrm{l})$ contained $10 \mathrm{mg} \mathrm{ml}^{-1}\left[\mathrm{U}^{14} \mathrm{C}\right] \mathrm{levan}$ in $0 \cdot 1 \mathrm{M}$ potassium phosphate, $\mathrm{pH} 6$. Reactions were initiated by addition of $E$. coli crude extracts (to a final concentration of 0.5 $\mathrm{mg} \mathrm{ml}^{-1}$ ). After $4 \mathrm{~h}$ incubation at $30^{\circ} \mathrm{C}$, the products of the hydrolysis were analysed by TLC (a) or chromatography on Biogel P60 (b). As a control, levan was incubated with $E$. coli crude extracts prepared from cells without the cloned $y v e B$ gene. (a) The TLC foil was developed twice in butan-1-ol/propan-2-ol/water (3:12:4, by vol.). Fructans with a degree of polymerization (DP) of more than 10 do not migrate and remain at the application site. (b) Chromatography on a Biogel P60 column $(1 \times 32 \mathrm{~cm})$. The radioactivity count was performed on each fraction $(1.5 \mathrm{ml})$ collected. Arrows indicate the void volume of the column (1), and the elution volumes of $\left[{ }^{14} \mathrm{C}\right]$ carboxymethylated inulin (5 $\left.\mathrm{kDa}\right)(2)$ and fructose (3).

. Control; $\bigcirc$, experimental.

$y v e A$ is $107 \mathrm{nt}$ distant from the stop codon of $y v e B$. This intergenic region includes a terminator structure and a Shine-Dalgarno sequence (AAAGGAG), 7 nt before the start codon of yveA (Fig. 2).

\section{Characterization of YveB as an endolevanase}

In view of the amino acid sequence similarity of YveB with levanase SacC, we could predict a levanase activity for YveB (SubtiList database: http://genolist.pasteur. fr/SubtiList/). Therefore, we tested the presence of levanase activity in the crude extracts obtained from an E. coli strain expressing the cloned yveB gene (see Methods). The crude extracts were incubated in the presence of high-molecular-mass $\left(>10^{7} \mathrm{Da}\right)$ levan uniformly $\left[{ }^{14} \mathrm{C}\right]$ labelled (Chambert \& Petit-Glatron, 1993). Products released by the enzyme action were analysed either by thin-layer chromatography (Fig. 3a), which indicated that the action of YveB on levan released small amounts of fructose and oligofructans with a low degree of polymerization (DP), or by chromatography on a Biogel P60 column (Fig. 3b), illustrating the size distribution of the products. The results show that oligofructosides spanning a molecular mass range of $1 \mathrm{kDa}$ to $10 \mathrm{kDa}$ (corresponding to a DP of fructosyl residues lower than 50) are the main products of the enzyme reaction. It can be concluded that $\mathrm{YveB}_{\mathrm{v}}$ mainly displays an endolevanase activity. The catalytic specificity of YveB is therefore different from that of SacC, which has been proved to be an exolevanase releasing only free fructose from its action on levan (Wanker et al., 1991). From this enzymic characterization, we hereafter rename YveB as LevB.
Since LevB is co-synthesized with SacB, we anticipated that these two enzymes could act synergistically on levan. Indeed, SacB has the dual catalytic activity of a levan polymerase and a levan hydrolase (Rapoport \& Dedonder, 1963). However, this latter exolevanase activity is arrested at the $2 \rightarrow 1$ branch points of the polymer levan. Thus, only $30 \%$ of available fructose is released by prolonged action of the enzyme on levan. When LevB and SacB acted together on levan, we observed (not shown) that the release of fructose was greater than that obtained by each enzyme separately with the same substrate since more than $60 \%$ of the polymer is hydrolysed to free fructose. This means that the endolevanase activity of LevB releases new sites on levan for the exolevanase activity of SacB. This property was used to characterize the localization of LevB in $B$. subtilis. In fact, the synergy of LevB and SacB activities mimics the activity of SacC, whose synthesis is induced by fructose during the stationary phase of growth. The possible effect of this property under in vivo conditions is discussed below.

\section{Localization of LevB in B. subtilis}

Culture supernatants, cytoplasmic and membrane fractions of induced and non-induced bacteria were obtained as described in Methods. In each fraction, levan hydrolytic activity was tested (Fig. 4a). Levanase activity of SacB was present in the culture supernatant and in the $2 \mathrm{M} \mathrm{KCl}$ washing supernatant of induced bacteria. In contrast, the catalytic activity of LevB, characterized by oligofructose release from levan, remained mainly associated with the membrane fraction 
(a)

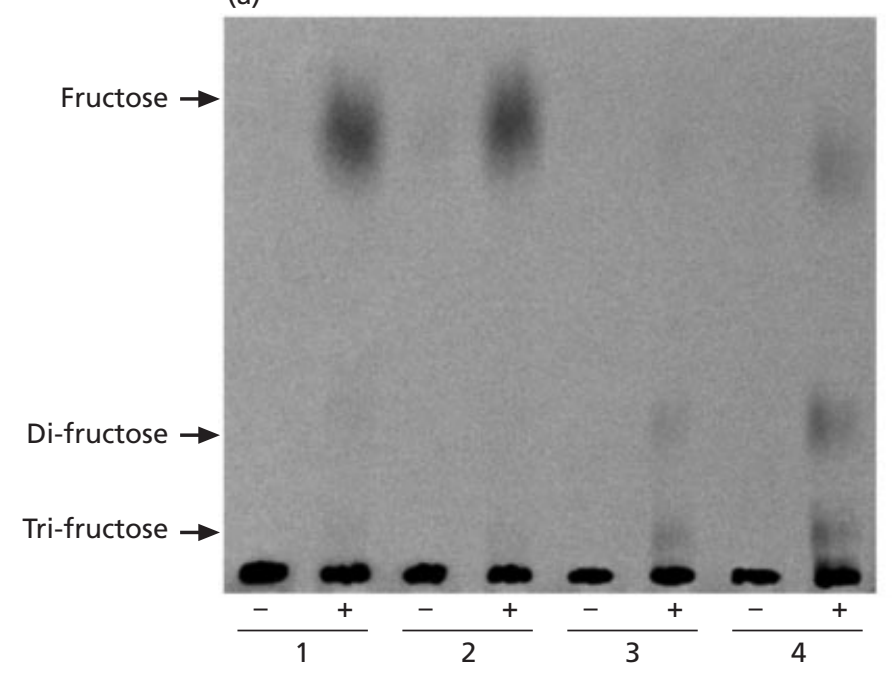

(b)

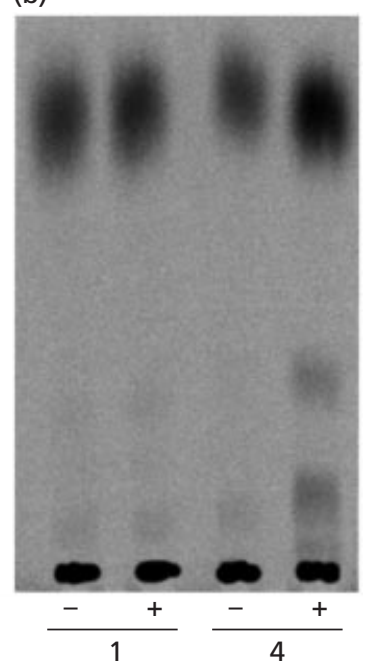

Fig. 4. Analysis of the cellular distribution of $\mathrm{SaCB}$ and LevB in B. subtilis degU32(Hy). A cell suspension at an $O D_{600}$ of $0 \cdot 2$ was divided into equal portions in flasks with $(+)$ or without $(-)$ sucrose, final concentration $50 \mathrm{mM}$. After $2 \mathrm{~h}$ growth $\left(\mathrm{OD}_{600} 1 \cdot 0\right)$, cell suspensions $(250 \mathrm{ml})$ were treated as described in Methods. (a) Levanase activity was tested by incubating $10 \mu \mathrm{l}\left[\mathrm{U}^{14} \mathrm{C}\right]$ levan solution with $10 \mu \mathrm{l}$ of (1) culture supernatant, (2) $2 \mathrm{M} \mathrm{KCl}$ washing supernatant of the cells, (3) cytoplasmic fraction, or (4) membrane fraction. After $4 \mathrm{~h}$ incubation at $30^{\circ} \mathrm{C}$, products were analysed by paper chromatography with $n$-butanol/acetic acid/water (4:1:1, by vol.) as developing solvent. (b) Levanase activity present in culture supernatant (1) and in membrane fraction (4) was assayed in the presence of $50 \mu \mathrm{g}$ pure levansucrase (SacB) $\mathrm{ml}^{-1}$.

of induced cells. This result was confirmed by the synergy of SacB and the membrane fraction, which led to an increase in levan hydrolysis (Fig. 4b). $30 \%$ fructose was released by $\mathrm{SacB}$ alone and $60 \%$ by a mixture of $\mathrm{SacB}$ and the membrane fraction. This result provided evidence that the hydrophobic $\mathrm{N}$-terminal sequence of this protein, which was proposed to be a cleavable signal peptide according to SignalP (Nielsen et al., 1997), could not be processed and consequently was more likely to be a membrane anchor as predicted by PSORT (Nakai $\&$ Kanehisa, 1991). This hypothesis is substantiated by the observation that, for the potential precursor form of this protein, the cleavage site of the leader peptidase is clearly unconventional when compared to that of SacB, a typical exocellular enzyme, secreted by the Secdependent pathway (Leloup et al., 1999b).

\section{DISCUSSION}

Northern blotting performed with the B. subtilis $\operatorname{deg} U 32(\mathrm{Hy})$ mutant indicated that transcription of $s a c B$, levB $(y v e B)$ and $y v e A$, three clustered genes, was triggered by sucrose. Hybridization of total RNA with specific probes showed that the transcript of $s a c B$, the proximal gene, is synthesized at a higher level than that of the other two genes. These latter were detected at lower levels as only bicistronic $s a c B-\operatorname{lev} B$ or tricistronic sacB-levB-yve $A$ transcripts, suggesting that these three genes constitute a sucrose-inducible tricistronic operon.

The difference in transcript levels in a same operon can be the result of two different mechanisms: either processing of the primary transcript and different stabilities of the processing products, or partial termination of transcription at internal termination structures. The absence of any $l e v B$ and $y v e A$ transcripts led us to favour the latter hypothesis. Furthermore, the intergenic regions between $s a c B-\operatorname{lev} B$ and $\operatorname{lev} B-y v e A$ were screened for the potential presence of a sigma $A$ promoter consensus (Haldenwang, 1995). Allowing four mismatches and a spacer of $17 \mathrm{nt}$ between the -35 and -10 sites, one promoter can be predicted in the intergenic region between $l e v B$ and $y v e A$, but in this case the -10 site would be only $7 \mathrm{nt}$ distant from the Shine-Dalgarno sequence, making a transcriptional start site in this region highly improbable, in agreement with the Northern blot analysis.

Modulation of the transcriptional level of the three genes of a same operon by partial termination of transcription at internal termination structures is perhaps related to a difference in the required quantities of the proteins encoded by the various genes. The protein products of $s a c B$ and $l e v B$ are both involved in sucrose metabolism, $s a c B$ encoding levansucrase, a wellcharacterized exocellular enzyme (Chambert et al., 1974), and levB encoding a protein which displays an endolevanase activity as shown in this study. The fact that LevB remains membrane associated could explain why its production is lower than that of levansucrase, since this latter exocellular enzyme is rapidly diluted in the cell environment and could therefore contribute to cell metabolism shortly after its synthesis.

The function of YveA, the third protein encoded by the 
operon, is unknown. Its numerous predicted transmembrane segments suggest a strong membrane association but the proposed amino acid permease similarity does not fit with the function of the two other genes, unless this protein mediates chemotactic responses to a variety of compounds like the Tar chemoreceptor of E. coli, which senses two quite different chemoeffectors, aspartate and maltose (Slocum \& Parkinson, 1983). Further studies are required to understand a possible link between the two metabolic pathways.

A similar operon organization of clustered genes encoding proteins involved in sucrose metabolism has been postulated from the DNA sequence of several micro-organisms, Bacillus stearothermophilus (Li et al., 1997; Naumoff, 1999), Gluconoacetobacter diazotrophicus (L. Hernandez and others, unpublished; see GenBank L41732) and Zymomonas mobilis (Song et al., 1999). Unfortunately, a lack of information about both the mechanism of the operon transcription and the enzyme specificity of the encoded proteins strongly limits any fruitful comparison with the B. subtilis operon characterized in this study.

\section{ACKNOWLEDGEMENTS}

We are grateful to Jérome Le Saux for technical assistance in continuous fermenter cultures, and members of the European Bacillus Secretion Group for valuable discussions during this work. We are also grateful to Antonia Kropfinger for revision of the English text. Y.P. was supported in part by a grant from ARC (Association pour la Recherche contre le Cancer), and this work was supported by grants from the European Commission (Biotech programme, BIO4-CT-960097, QLK3CT-1999-00413).

\section{REFERENCES}

Aymerich, S. \& Steinmetz, M. (1992). Specificity determinants and structural features in the RNA target of the bacterial antiterminator proteins of the BglG/SacY family. Proc Natl Acad Sci U S A 89, 10410-10414.

Chambert, R. \& Petit-Glatron, M. F. (1984). Hyperproduction of exocellular levansucrase by Bacillus subtilis: examination of the phenotype of a $s a c U^{\mathrm{h}}$ strain. J Gen Microbiol 130, 3143-3152.

Chambert, R. \& Petit-Glatron, M. F. (1993). Immobilisation of levansucrase on calcium phosphate gel strongly increases its polymerase activity. Carbohydr Res 244, 129-136.

Chambert, R., Tréboul, G. \& Dedonder, R. (1974). Kinetic studies of levansucrase of Bacillus subtilis. Eur J Biochem 41, 285-300.

Crutz, A. M., Steinmetz, M., Aymerich, S., Richter, R. \& Le Coq, D. (1990). Induction of levansucrase in Bacillus subtilis: an antitermination mechanism negatively controlled by the phosphotransferase system. J Bacteriol 172, 1043-1050.

Haldenwang, W. (1995). The sigma factors of Bacillus subtilis. Microbiol Rev 59, 1-30.

Kunst, F. Ogasawara, N., Moszer, I. \& 148 other authors (1997). The complete genome sequence of the Gram-positive bacterium Bacillus subtilis. Nature 390, 249-256.

Leloup, L., Haddaoui, E., Chambert, R. \& Petit-Glatron, M. F. (1997). Characterization of the rate limiting step of the secretion of Bacillus subtilis $\alpha$-amylase overproduced during the exponential phase of growth. Microbiology 143, 3295-3303.

Leloup, L., Le Saux, J., Petit-Glatron, M. F. \& Chambert, R. (1999a). Kinetics of the secretion of Bacillus subtilis levanase overproduced during the exponential phase of growth. Microbiology 145, 613-619.

Leloup, L., Chambert, R. \& Petit-Glatron, M. F. (1999b). Differential dependence of levansucrase and alpha-amylase secretion on SecA (Div) during the exponential phase of growth of Bacillus subtilis. J Bacteriol 181, 1820-1826.

Lepesant, J. A., Kunst, F., Lepesant-Kejzlarova, J. \& Dedonder, R. (1972). Chromosomal location of mutations affecting sucrose metabolism in Bacillus subtilis Marburg. Mol Gen Genet 118, 135-160.

Li, Y., Triccas, J. A. \& Ferenci, T. (1997). A novel levansucraselevanase gene cluster in Bacillus stearothermophilus ATCC12980. Biochim Biophys Acta 1353, 203-208.

Nakai, K. \& Kanehisa, M. (1991). Expert system for predicting protein localization sites in Gram-negative bacteria. Proteins 11, 95-110.

Naumoff, D. G. (1999). Homologous locus of Bacillus subtilis and Bacillus stearothermophilus genomes containing levansucrase and levanase genes. Mol Biol 33, 173-176.

Nielsen, H., Engelbrecht, J., Brunak, S. \& von Heijne, G. (1997). A neural network method for identification of prokaryotic and eukaryotic signal peptides and prediction of their cleavage sites. Int J Neural Syst 8, 581-599.

Pereira, Y., Chambert, R., Leloup, L., Daguer, J. P. \& Petit-Glatron, M. F. (2001). Transcripts of the genes $s a c B$, amyE, sacC and $c s n$ expressed in Bacillus subtilis under the control of the $5^{\prime}$ untranslated $s a c R$ region display different stabilities that can be modulated. Microbiology 147, 1331-1341.

Rapoport, G. \& Dedonder, R. (1963). La lévane saccharase de Bacillus subtilis. II. Hydrolyse et transfert à partir des lévanes. Bull Soc Chim Biol 45, 493-513.

Sambrook, J., Fritsch, E. F. \& Maniatis, T. (1989). Molecular Cloning: a Laboratory Manual, 2nd edn. Cold Spring Harbor, NY : Cold Spring Harbor Laboratory.

Shimotsu, H. \& Henner, D. J. (1986). Modulation of Bacillus subtilis levansucrase gene expression by sucrose and regulation of steady-state mRNA level by $s a c U$ and sacQ genes. J Bacteriol 168 , 380-388.

Slocum, M. K. \& Parkinson, J. S. (1983). Genetics of methyl accepting chemotaxis proteins in Escherichia coli: organization of the Tar region. J Bacteriol 155, 565-577.

Song, K. B., Seo, J. W. \& Rhee, S. K. (1999). Transcriptional analysis of $l e v U$ operon encoding saccharolytic enzymes and two apparent genes involved in amino acid biosynthesis in Zymomonas mobilis. Gene 232, 107-114.

Steinmetz, M. \& Aymerich, S. (1986). Genetic analysis of $s a c R$, a cis-regulator of levan-saccharase synthesis of Bacillus subtilis. Ann Inst Pasteur Microbiol 137A, 3-14.

Steinmetz, M., Le Coq, D., Aymerich, S., Gonzy-Tréboul, G. \& Gay, P. (1985). The DNA sequence of the gene for the secreted Bacillus subtilis enzyme levansucrase and its genetic control sites. Mol Gen Genet 200, 220-228.

Tjalsma, H., Bolhuis, A., Jongbloed, J. D., Bron, S. \& van Dijl, J. M. (2000). Signal peptide-dependent protein transport in Bacillus subtilis: genome-based survey of the secretome. Microbiol Mol Biol Rev 64, 515-547.

Tortosa, P. \& Le Coq, D. (1995). A ribonucleic antiterminator sequence (RAT) and a distant palindrome are both involved in 
sucrose induction of the Bacillus subtilis sacXY regulatory operon. Microbiology 141, 2921-2927.

Wanker, E., Schörgendorfer, K. \& Schwab, H. (1991). Expression of the Bacillus subtilis levanase gene in Escherichia coli and Saccharomyces cerevisiae. J Biotechnol 18, 243-254.

Zuker, M., Mathews, D. H. \& Turner, D. H. (1999). Algorithms and thermodynamics for RNA secondary structure prediction. A practical guide. In RNA Biochemistry and Biotechnology, pp. 11-43. Edited by J. Barciszewski \& B. F. C. Clark. Dordrecht: Kluwer.

Received 5 June 2001; revised 13 August 2001; accepted 23 August 2001. 